\section{University Earth scientists are preparing for reorganization}

\section{London}

RESTRUCTURING an entire scientific discipline within a nation's university system is fraught with political and practical difficulties, as Britain's beleaguered geoscientists and the University Grants Committee (UGC) are discovering.

Last May, at the UGC's request, a committee under Professor E.R. Oxburgh produced a report suggesting a way of making more efficient use of the funds available for teaching and research in the Earth sciences in Britain's universities. Oxburgh's solution was to create three tiers of university department - some (about ten) equipped for research and teaching to an international standard, some equipped for the full range of teaching but with little research capability and some providing undergraduates with an understanding of the Earch sciences, probably contained within other departments, such as physics. The departments would be classified as types 1,2 and 3, respectively.

After extensive consultation, modifications to the Oxburgh report were agreed, where two types of department would be created. Type A departments would be involved in research and honours degree teaching, and would not normally have less than the equivalent of 180 full-time students, and a staff:student ratio of about $1: 9$; there would probably be fewer than 20 Type A departments.

Type B departments would be contained within other departments, such as physics, and would not normally be equipped to teach single honours. Superimposed on the two-tier system would be equipment centres within a limited number of the larger departments, concentrating expensive analytical equipment. The UGC initally implied that there would be about five such centres, and that their locations would be designated before universities invited to submit bids to operate either Type A or Type B departments. The proposal was condemned by the heads of the geoscience departments, who argued that no individual department should be required to service heavy equipment across the entire range of Earth sciences and its subdisciplines, and that distribution of equipment should be decided during the bid process and not precede it. The modifications have been adopted by the UGC.

The UGC has set itself an ambitious timetable. Finalized bids must be submitted by 1 January 1988, with the new system operating by the beginning of the academic year 1988-89. One national and three regional committees have been set up to see that the whole process runs smoothly, and an 'equipment rationalization committee' will decide where to put expensive experimental and analytical apparatus.

For the heads of departments, the task of compiling a bid is proving monumental. The UGC requires detailed completion of a 55-page questionnaire, with information ranging from the age of academic staff to five years' worth of publication and citation data. Academics are complaining that faced with such a daunting task, routine research and teaching is suffering. Privately, many feel that the bid process has been reduced to a number-shuffling exercise, with the object of arriving at the required staff:student ratio in order to qualify for Type A department status. In some cases this has meant merger negotiations with neighbouring institutions or, possibly with more damaging implications, with neighbouring departments within an institution. The difficulty arises with disciplines on the periphery of Earth sciences, such as meteorology or oceanography, that now reside within nonEarth-science departments. At the University of Newcastle upon Tyne, for example, geophysics forms part of the physics department. If it were lumped in with geology in order to produce a feasible 'Type A' bid (something that has been discussed but seems unlikely to go ahead), one of the country's largest universities would be left with an unviable physics department.

Simon Hadlington

\section{Well done, Pioneer}

\section{Washington}

Pioneer 8, designed to send back signals from interplanetary space for six months, has done quite a bit better than that.

Earlier this week it marked 20 years on the job, and is still sending back data from one of its experimental packages.

Pioneer 8 was the third in a series of four satellites launched in the 1960 s to study solar flares and related phenomena. Of the eight instruments on the spacecraft, only the electric field detector is now operating.

From 1971 to 1984 the spacecraft was powered down to save the cost of monitoring the telemetry and to conserve power. But when the more sophisticated electric field detector on Pioneer 9 failed, Pioneer 8 was powered up in time to send information back when spacecraft's orbit sent it through the Earth's magnetic wake.

Also this week, Pioneer 6 celebrates its twenty-second year of operation, making it the oldest functioning spacecraft in interplanetary space.

\section{New European telescope for the Andes}

Paris

THE European Southern Observatory (ESO), whose headquarters are in West Germany, has given the official go-ahead for a new telescope in northern Chile. The decision came with the announcement last week that France will release FF338 million ( $£ 33.8$ million) over ten years as a contribution to the cost of building the Very Large Telescope (VLT).

West Germany has already promised an equal amount, 26.7 per cent of the total,

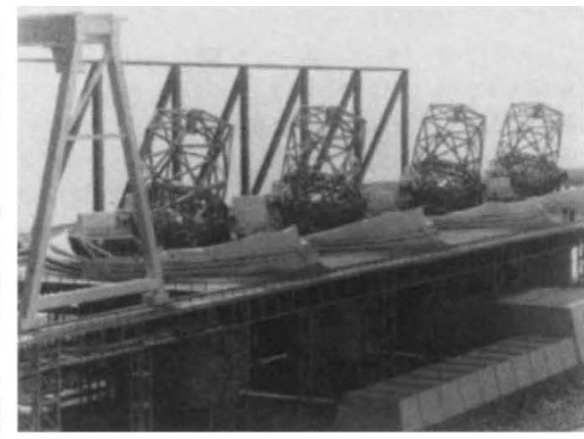

A model of the four connected telescopes that make up the Very Large Telescope.

and Italy a slightly smaller amount. The remainder will come from ESO's other five member states: Belgium, Denmark, the Netherlands, Sweden and Switzerland. Although Belgium is not yet committed, more than 75 per cent of the cost has been pledged, making it possible to award some of the contracts for mirror manufacturing and polishing.

VLT will eventually comprise four 8-m telescopes, giving it a power equivalent of a single $16-\mathrm{m}$ telescope, greater than the US Keck telescope which will be built in Hawaii in 1990. Coupling the telescopes together to form an interferometric array involves, says Dr Couturier of Institut National des Sciences de l'Univers in Paris, "a technical gamble, but ESO is confident that it will pay off". Working in this mode, VLT will have resolution five times greater than any existing Earth-based telescope.

Two sites have been proposed for VLT the present ESO site at La Silla at an altitude of $2,400 \mathrm{~m}$, where 13 telescopes are already in operation, or a new site at Cerro Paranal, at $2,700 \mathrm{~m}$. A decision will be needed by 1990 for the installation and operation of the first telescope at the end of 1993.

New techniques of mirror design and of active surface control will be needed to construct the telescopes which, once installed, will be able to operate remotely from the ESO centre at Garching, near Munich. 